\title{
Biodegradation of Styrene-Butadiene-Styrene Coploymer via Sugars Attached to the Polymer Chain
}

\author{
Rakesh Singh $^{1}$, Rishi Gupta ${ }^{2}$, Mukund G. Adsul ${ }^{3}$, Ramesh C. Kuhad ${ }^{2}$, \\ Digambar V. Gokhale ${ }^{3}$, Anjani J. Varma ${ }^{*}$ \\ ${ }^{1}$ Polymer Science \& Engineering Division, National Chemical Laboratory, Pune, India \\ ${ }^{2}$ Department of Microbiology, University of Delhi (South Campus), New Delhi, India \\ ${ }^{3}$ National Collection of Industrial Microorganisms, Biochemical Sciences Division, National Chemical Laboratory, Pune, India

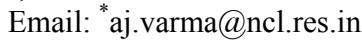

Received March 21, 2013; revised May 2, 2013; accepted May 12, 2013

Copyright (C) 2013 Rakesh Singh et al. This is an open access article distributed under the Creative Commons Attribution License, which permits unrestricted use, distribution, and reproduction in any medium, provided the original work is properly cited.

\begin{abstract}
A synthetic method was developed to chemically attach few molecules of simple sugars like glucose, mannose, galactose, maltose and xylose $(0.09-0.37 \mathrm{wt} \%)$ and with quaternary nitrogen pendants $(0.42-0.46$ atomic\%) along the polybutadiene section of polystyrene-block-polybutadiene-block-polystyrene (SBS) block copolymer. These functionalized SBS copolymers were evaluated for biodegradation using the fungal culture Aspergillus niger NCIM 1025 (ATCC 9642) and bacterial culture Pseudomonas sp. NCIM 2220, and for antimicrobial properties using bacteria E. coli DH5 $\alpha$ and Bacillus subtilis and yeasts Pichia stipitis NCIM 3497 and P. stipitis NCIM 3499. It was conclusively demonstrated that these modified SBS block copolymers were significantly more biodegradable than the unmodified SBS; the observed weight loss after biodegradation was $\sim 4$ - 14-fold for bacterial and $\sim 7$ - 36-fold for fungal cultures with respect to the sugar content of modified SBS. Preliminary studies on antimicrobial properties of these biodegradable polymers showed a $4 \%-24 \%$ decrease in growth of the microorganisms E. coli and Bacillus subtilis studied.
\end{abstract}

Keywords: Biodegradation; Antimicrobial; SBS; Sugar; Quaternary Nitrogen

\section{Introduction}

Commodity elastomers like SBS have become an integral part of our society. However, these synthetic polymers resist microbial degradation when discarded in landfills. One possible method of introducing biodegradability into non-biodegradable hydrocarbon polymers is to introduce some functional groups along the SBS polymer chain [1]. A functional group when incorporated into a polymer can deliver enhanced properties, such as biocompatibility [2], antimicrobial property [3], biodegradation [4] etc., as evidenced by numerous reports in scientific literature. Synthesis of synthetic polymers having sugar branches (synthetic glycopolymers) has become an interesting area of work because of the importance of these materials as renewable materials and also due to their numerous biological and biomedical applications, including use as biodegradable polymers.

Although some aspects of functionalization of polybutadiene, such as synthesis of hydroxy-terminated polybutadiene and reaction of epoxidized cis-1,4-polybuta-

${ }^{*}$ Corresponding author. diene with p-aminodiphenylamine to obtain antioxidant properties [5-7], and functionalization of low molecular weight oligomers of poly(butadiene-co-acrylic acid) with sucrose $[8,9]$ have been studied, there are no reports on functionalization of SBS with sugars. While there exists a significant body of literature on biodegradable plastics, there are hardly any reports on introducing biodegradability to synthetic elastomers like SBS. Such biodegradable elastomers can have interesting applications in packaging applications because of their film forming abilities.

It has previously been demonstrated in our lab that functionalization of maleated polystyrenes with minute quantities of sugars leads to a significant increase in the extent of their biodegradation $[10,11]$. Our very recent work has further demonstrated that functionalization of a commodity elastomer like SBS with sugars is possible by employing click chemistry technique; preliminary studies showed such polymers biodegrade to a significant extent [12]. In this paper we present our more detailed work on biodegradation of such polymers, including evaluating the changes occurring in their antimicrobial properties, 
since these polymers also contain some quaternary nitrogen atoms in the form of pyridinium groups onto the backbone of the polybutadiene fraction of SBS polymer [13].

Biodegradation studies were conducted for a period of 30 days using pure soil fungal and bacterial cultures. The fungal culture used in this study was Aspergillus niger (NCIM 1025) and the bacterial culture was Pseudomonas sp. (NCIM 2220). Biodegradation was monitored by weight loss in case fungal culture and by optical density (OD) in case of bacterial culture. The observed degradation was further corroborated using SEM studies of the elastomer before and after biodegradation. The effect of minute quantities $(0.42-0.46$ atomic $\%)$ of quaternary nitrogen pendants on biodegradation and antimicrobial properties was also evaluated.

\section{Experimental}

\subsection{Materials}

SBS $\left(\mathrm{M}_{\mathrm{w}} 140,000,30 \%\right.$ polystyrene, $70 \%$ polybutadiene $)$ was obtained from Aldrich, USA, Chloroform (HPLC grade) was purchased from Spectrochem, while isopropyl alcohol (HPLC grade) was purchased from SRL, India.

\subsection{Synthesis of Sugar Linked SBS}

Sugar molecules (glucose, glucose, mannose, galactose, maltose and xylose) and quaternary nitrogen were anchored into SBS by a procedure reported earlier $(12,13)$. The sugar content of all the sugar linked SBS was determined by phenol sulphuric acid assay [14]. Details of the composition of the polymers are given in Table 1. The chemical structure of one representative SBS molecule with glucose anchored on it by click chemistry technique is shown in the Scheme 1.

\subsection{Scanning Electron Microscopy (SEM)}

The surface morphology of SBS and functionalized SBS was investigated using Leica SEM stereoscan 440, Cambridge, UK. In order to achieve conducting surface, the polymeric samples in the form of thin films, were coated with gold in a sputter coater.

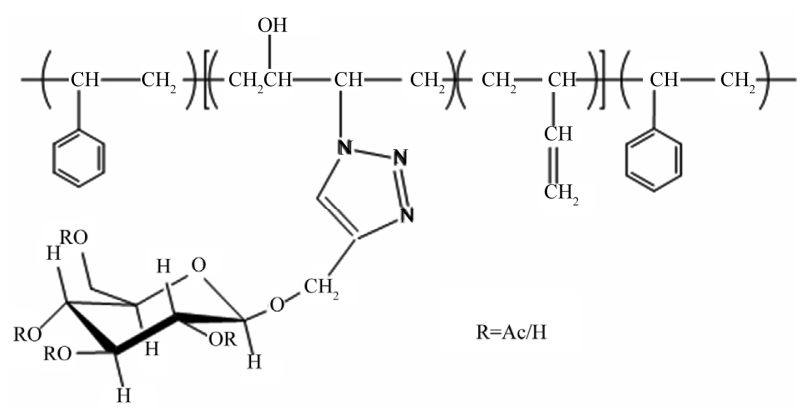

Scheme 1. Idealized structure of glucose/acetylated glucose attached to the polybutadiene fraction of SBS (see ref. [12]).
Table 1. Surface composition of functionalized SBS polymers films for sugar and nitrogen content by different techniques.

\begin{tabular}{ccccc}
\hline Sample & $\begin{array}{c}\text { Sugar }^{\mathrm{a}} \\
\text { Content } \\
(\mathrm{wt} \%)\end{array}$ & $\begin{array}{c}\text { Nitrogen }^{\mathrm{b}} \\
\text { Content }(\mathrm{at} \%) \\
\text { (Total) }\end{array}$ & $\begin{array}{c}\mathrm{N}^{\mathrm{b}}(\mathrm{at} \%) \\
\text { (Cationic) }\end{array}$ & $\begin{array}{c}\mathrm{N}^{\mathrm{b}} \text { (at \%) } \\
(\text { Neutral) }\end{array}$ \\
\hline SBS & 0.00 & $\mathrm{NA}$ & $\mathrm{NA}$ & $\mathrm{NA}$ \\
SBS Epoxide & 0.00 & $\mathrm{NA}$ & $\mathrm{NA}$ & $\mathrm{NA}$ \\
Galactose Linked SBS & 0.16 & 1.53 & 0.42 & 1.11 \\
Maltose Linked SBS & 0.37 & 1.68 & 0.46 & 1.22 \\
Mannose Linked SBS & 0.12 & $\mathrm{ND}^{\mathrm{c}}$ & $\mathrm{ND}^{\mathrm{c}}$ & $\mathrm{ND}^{\mathrm{c}}$ \\
Xylose Linked SBS & 0.11 & $\mathrm{ND}^{\mathrm{c}}$ & $\mathrm{ND}^{\mathrm{c}}$ & $\mathrm{ND}^{\mathrm{c}}$ \\
\hline
\end{tabular}

${ }^{\mathrm{a}}$ As determined by phenol-sulphuric acid assay; ${ }^{\mathrm{b}}$ As determined by XPS; ${ }^{c}$ Expected to be in the range of 1.5 to 1.7 at $\%$; ND: not determined; NA: not applicable.

\subsection{Preparation of Polymeric Films}

Sugar functionalized SBS containing quaternary nitrogen pendants were dissolved in $\mathrm{CHCl}_{3}$ with overnight stirring to ensure dissolution. $10 \%(\mathrm{w} / \mathrm{v})$ solutions of these polymers were cast into films in Petri dishes by slowly evaporating the chloroform solution at room temperature. These films were used for antimicrobial activity studies.

\subsection{Biodegradation}

The microorganisms Aspergillus niger NCIM 1025 (ATCC 9642) and Pseudomonas sp. NCIM 2220 were obtained from the National Collection of Industrial Microorganisms, National Chemical Laboratory, Pune, India. These cultures were routinely maintained on Potato Dextrose Agar (PDA) slopes. The methodology followed was the same as our earlier published work [10,11].

\subsection{Minimal Medium Preparation}

\subsubsection{Fungal Culture}

The culture was grown in minimal medium (ASTM Nutrient Salts Medium) containing (g/l): $\mathrm{KH}_{2} \mathrm{PO}_{4}$ 0.7; $\mathrm{K}_{2} \mathrm{HPO}_{4} \quad 0.7 ; \quad \mathrm{MgSO}_{4} \cdot 7 \mathrm{H}_{2} \mathrm{O} \quad 0.7 ; \mathrm{NH}_{4} \mathrm{NO}_{3} \quad 1.0 ; \mathrm{NaCl}$ 0.005; $\mathrm{FeSO}_{4} \cdot 7 \mathrm{H}_{2} \mathrm{O}$ 0.002.; $\mathrm{ZnSO}_{4} \cdot 7 \mathrm{H}_{2} \mathrm{O}$ 0.002.; $\mathrm{MnSO}_{4}$. $\mathrm{H}_{2} \mathrm{O} 0.001$. The $\mathrm{pH}$ of the medium was adjusted to $6.5 \pm$ 0.2 and sterilized at $121^{\circ} \mathrm{C}$ for 20 minutes.

\subsubsection{Bacterial Culture}

Cultures were grown in Minimal medium (OECD) containing (g/l): $\left(\mathrm{NH}_{4}\right)_{2} \mathrm{SO}_{4}, 2.0 ; \mathrm{K}_{2} \mathrm{HPO}_{4}, 14.0 ; \mathrm{KH}_{2} \mathrm{PO}_{4}$, $6.0 ; \mathrm{MgSO}_{4} .7 \mathrm{H}_{2} \mathrm{O}, 0.2$. The $\mathrm{pH}$ of the medium was adjusted to 7.0 prior to sterilization. The medium was sterilized at $121^{\circ} \mathrm{C}$ for $20 \mathrm{~min}$.

\subsubsection{Testing of the Samples}

The test samples were surface sterilized with $70 \%$ ethanol 
overnight and then added separately to the sterilized medium. The cells of the cultures grown in $10 \mathrm{~mL}$ Nutrient broth for $24 \mathrm{~h}$ at $30^{\circ} \mathrm{C}$ were suspended in $10 \mathrm{ml}$ of saline and this suspension was used as an inoculum. Approximately $1 \mathrm{~mL}\left(\sim 10^{8}\right.$ cells) was inoculated into $50 \mathrm{ml}$ of the minimal medium in $250 \mathrm{ml}$ conical flasks. The flasks were incubated at $28^{\circ} \mathrm{C}$ with shaking at $180 \mathrm{RPM}$. The growth was monitored over a period of four weeks. For bacterial culture optical density was measured at regular interval using Systronics 117 spectrophotometer. After 30 days the polymer was separated from the cells. The polymer was further washed many times with water followed by washing with $70 \%$ ethanol. It was dried at $50^{\circ} \mathrm{C}$ and analyzed by scanning electron microscopy (SEM). Percentage weight losses of the polymers were also recorded.

\subsection{Antimicrobial Activity}

The bacterial cultures (E. coli DH5 $\alpha$ and Bacillus subtilis RCK (Accession no. AJ937677; this culture has been deposited in the National Centre of Biotechnology Information (NCBI) Genbank in India), were procured from the culture collection of Lignocellulose Biotechnology Laboratory, Department of Microbiology, University of Delhi South Campus, New Delhi, India, and were maintained on Luria-Bertani (LB) agar plates at $37^{\circ}$ C. Pichia stipitis NCIM 3497 and P. stipitis NCIM 3499 were procured from National Collection of Industrial Microorganisms, National Chemical Laboratory, Pune, India and were maintained at $30^{\circ} \mathrm{C}$ on YPD medium containing $(\mathrm{g} / \mathrm{L})$ : Yeast extract 3.0, Peptone 5.0, Dextrose 20.0, agar 20.0 and $\mathrm{pH}$ 5.5. All cultures were subcultured fortnightly and stored at $4{ }^{\circ} \mathrm{C}$.

For the inoculum preparation of bacterial culture, a loopful of cell mass from pre-grown agar plates was inoculated into sterile $50 \mathrm{~mL}$ Luria-Bertani (LB) broth in a $250 \mathrm{~mL}$ Erlenmeyer flask and incubated at $37^{\circ} \mathrm{C}$ and 200 $\mathrm{rpm}$ for $16 \mathrm{~h}$. While, the inoculum of yeast cultures was prepared by inoculating a loop-full of cell mass from pre-grown agar plates into $50 \mathrm{~mL}$ of YPD broth in a 250 $\mathrm{mL}$ Erlenmeyer flask and incubated at $30^{\circ} \mathrm{C}$ and $150 \mathrm{rpm}$ for $24 \mathrm{~h}$.

Anti-microbial effect of the polymeric films was studied by adding $25.0 \mathrm{mg}$ of each film separately in $50.0 \mathrm{~mL}$ sterilized LB broth for bacterial cultures and YPD broth for yeasts, in $250.0 \mathrm{~mL}$ Erlenmeyer flasks. Each flask was inoculated with bacterial or yeast culture $(0.2 \% \mathrm{v} / \mathrm{v})$ grown for 16 and $24 \mathrm{~h}$, respectively. The bacterial cultures were incubated at $37^{\circ} \mathrm{C}$ and $200^{\circ} \mathrm{C} \mathrm{rpm}$ in a rotatory incubator shaker, while the yeasts were grown at $30^{\circ} \mathrm{C}$ and $150^{\circ} \mathrm{C} \mathrm{rpm}$. The samples from each flask were taken after 24 . The cell growth was analyzed by measuring the optical density (OD) at $600 \mathrm{~nm}$ in a UV-Vis spectrophotometer (Analytical Jena, Specord 205, Germany). The flask without the polymeric films served as control.

\section{Result and Discussions}

The functionalized SBS elastomers were characterized for sugar and nitrogen content. The sugar content of the functionalized SBS ranged from $0.09-0.37$ (weight $\%$ ). Atomic concentration (\%) of these elastomers was determined by XPS analysis and the total nitrogen content as determined ranged from $1.53-1.68$ (atomic wt\%), as summarized in Table 1.

\subsection{Biodegradation Studies of Sugar Linked SBS}

We anchored minute quantities of various sugars like glucose, galactose, mannose, xylose, maltose and sucrose with the aim of improving biodegradation of SBS. Instead of using a mixture of several microorganisms, we chose a single soil bacterial culture (Pseudomonas sp.) and fungal culture (Aspergillus niger) for investigating their individual growth patterns on these new SBS elastomers, and compared their growth with that of a control solutions containing unmodified SBS elastomer as well as without any polymers.

\subsection{Bacterial Biodegradation by Pseudomonas} sp.

Test organisms used in the present study were standard cultures used for testing samples for their bacterial resistance. The test cultures used in the present study are organisms widely found in the environment. However, use of pure culture system offers the advantage of reproducibility of results, and would aid in designing biodegradation systems for different polymers after their disposal as waste materials. Since Pseudomonas sp. is a common soil bacteria, therefore these results have implication for disposal of these polymers in soil for obtaining biodegradation. The bacteria mediated biodegradation of sugar linked SBS by Pseudomonas sp. is presented in Figure 1.

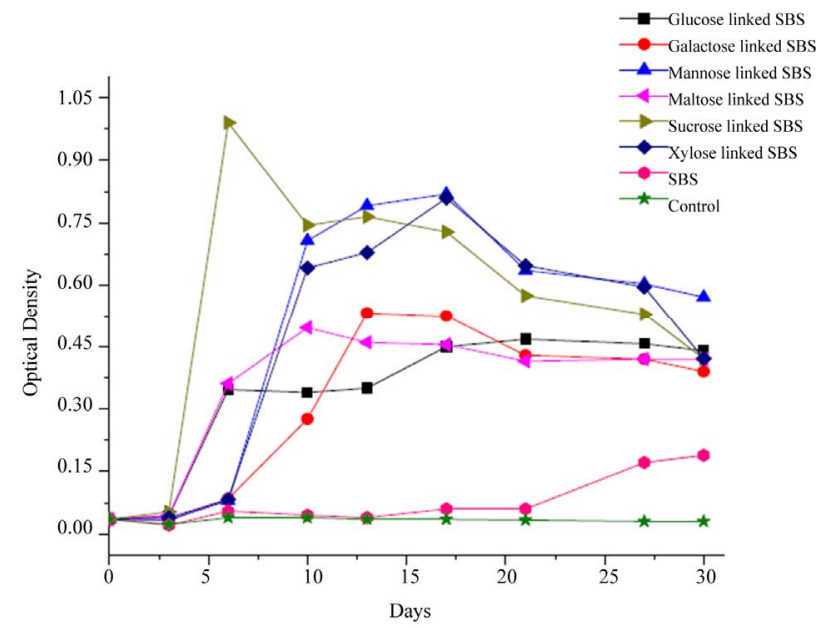

Figure 1. Growth pattern of Pseudomonas sp. on different sugars linked SBS. 
From the growth pattern of Pseudomonas sp. on different monomeric sugars linked SBS, it can be observed that the rates of increase in optical density (reflecting material degradation) in sugars linked SBS is much higher than the unmodified SBS and the control. The galactose linked SBS showed OD maximum in two weeks, whereas the glucose and mannose liked SBS showed a maximum after two weeks. The mannose derivative showed significant increase in OD as compared to glucose and galactose linked SBS. However, it may be pointed out that the total weight loss after degradation is still insufficient to classify the modified SBS as a biodegradable material, even though the weight loss is several times the weight of the sugar attached. Therefore, though this strategy is promising, it needs another innovation to take it to the next level of biodegradation.

From the Figure 1, it is observed that the sucrose linked SBS was more degradable as compared to the maltose linked SBS. Sucrose linked SBS showed the highest OD among all the sugar linked SBS. For Pseudomonas sp. (NCIM 2220), the extent of biodegradation based on increase in optical density evaluated in the context of the extent of sugar incorporated, is as follows: sucrose $>$ maltose $>$ mannose $>$ glucose $>$ galactose $>$ xylose.

This can also be discerned from the weight loss data presented in Tables 2 and $\mathbf{3}$ where the ratio of percent weight loss and percent sugar content of the sugar-linked SBS using bacterial and fungal cultures respectively. Due to the adherence of bacterial cells onto the polymer, the observed weight losses are generally lesser than expected. It is reported that in many such cases, weight loss data are inconclusive due to cell wall accumulation. From Table 2, we observe that SBS and partially epoxidized SBS without any sugar linked to it are not degraded by bacterial culture whereas the sugar linked SBS showed

Table 2. Weight loss data for bacterial degradation using Pseudomonas sp. over a period of 30 days.

\begin{tabular}{|c|c|c|c|c|c|}
\hline Sample & $\begin{array}{l}\text { Initial } \\
\text { Weight } \\
\text { (mg) }\end{array}$ & $\begin{array}{c}\text { Final } \\
\text { Weight } \\
\text { (mg) }\end{array}$ & $\begin{array}{c}\% \\
\text { Weight } \\
\text { loss }\end{array}$ & $\begin{array}{c}\text { Sugar } \\
\text { Content } \\
(\text { Weight \%) }\end{array}$ & $\begin{array}{c}\text { \% Wt. Loss/ } \\
\text { \% Sugar } \\
\text { Content }\end{array}$ \\
\hline SBS & 250 & 250 & 0.0 & 0.0 & - \\
\hline SBS Epoxide & 250 & 250 & 0.0 & 0.0 & - \\
\hline $\begin{array}{c}\text { Glucose Linked } \\
\text { SBS }\end{array}$ & 250 & 248.50 & 0.6 & 0.09 & 6.7 \\
\hline $\begin{array}{c}\text { Mannose Linked } \\
\text { SBS }\end{array}$ & 250 & 247 & 1.2 & 0.12 & 10 \\
\hline $\begin{array}{c}\text { Galactose Linked } \\
\text { SBS }\end{array}$ & 250 & 247.20 & 0.9 & 0.16 & 5.6 \\
\hline Xylose Linked SBS & 250 & 249 & 0.4 & 0.11 & 3.6 \\
\hline Maltose Linked SBS & 250 & 240.20 & 3.9 & 0.37 & 10.5 \\
\hline Sucrose Linked SBS & 250 & 239 & 4.4 & 0.32 & 13.8 \\
\hline
\end{tabular}

Table 3. Weight loss of the sugar-linked polymers degraded by fungal strain Aspergillus niger.

\begin{tabular}{cccccc}
\hline Sample & $\begin{array}{c}\text { Initial } \\
\text { Weight } \\
(\mathrm{mg})\end{array}$ & $\begin{array}{c}\text { Final } \\
\text { Weight } \\
(\mathrm{mg})\end{array}$ & $\begin{array}{c}\% \\
\text { Weight } \\
\text { Loss }\end{array}$ & $\begin{array}{c}\text { Sugar } \\
\text { Content } \\
\text { (Weight \%) }\end{array}$ & $\begin{array}{c}\% \text { Wt. Loss/ } \\
\% \text { Sugar } \\
\text { Content }\end{array}$ \\
\hline SBS & 250 & 250 & 0.0 & 0.0 & - \\
$\begin{array}{c}\text { SBS Epoxide } \\
\text { Glucose Linked } \\
\text { SBS }\end{array}$ & 250 & 250 & 0.0 & 0.0 & - \\
$\begin{array}{c}\text { Mannose Linked } \\
\text { SBS }\end{array}$ & 250 & 241.80 & 3.3 & 0.09 & 36.7 \\
$\begin{array}{c}\text { Galactose Linked } \\
\text { SBS }\end{array}$ & 250 & 247.30 & 1.1 & 0.16 & 6.9 \\
$\begin{array}{c}\text { Maltose Linked SBS } \\
\begin{array}{c}\text { Sucrose Linked SBS } \\
\text { SBS }\end{array}\end{array} 250$ & 234.10 & 6.3 & 0.37 & 17.0 \\
\hline
\end{tabular}

significant weight losses ranging from $\sim 4-14$ fold for the bacterial culture used in this study. This extent of weight loss is indicative of some polymer chain scission having also taken place along with the loss of sugar during biodegradation.

\subsection{Weight Loss Data for Fungal Degradation of Sugar Linked SBS}

Biodegradation of different sugar linked SBS was also studied with the fungal culture Aspergillus niger (NCIM 1025, ATCC 9642). Table 3 shows the weight data of the different sugar linked SBS after biodegradation. It is seen that weight loss varies with the type of sugar anchored and sugar content of the functionalized SBS. As in the case of bacterial biodegradation, here also the ratio of percent weight loss and percent sugar attached to SBS is as high as 36.7. SBS and epoxidized SBS having no sugar attached to them and was not degraded by the fungal culture.

The visual growth of the fungus (Aspergillus niger NCIM 1025) is seen from the photograph in Figure 2.

For Aspergillus niger (NCIM 1025, ATCC 9642) the extent of biodegradation based on weight loss evaluated in the context of the extent of sugar incorporated, is as follows: glucose $>$ maltose $>$ sucrose $>$ mannose $>$ galactose.

While the exact mechanism is still the subject of research, such findings have been reported before, with data proving reduction in molecular weight of the polystyrene polymer [10].

\subsection{Scanning Electron Micrographs (SEM) of the Sugar Linked SBS after Degradation by Fungal Culture Aspergillus niger (NCIM 10,259)}

The SEM of sugar linked SBS after biodegradation was recorded to investigate the morphological changes induced 
by biodegradation. Some representative samples were chosen in the form of films. After biodegradation the films were thoroughly washed with water to remove the adhering bacteria and fungus and were suspended in $70 \%$ ethanol and dried.

Figure 3 shows the morphology of the unmodified SBS and epoxidized SBS after biodegradation. There seems to be practically no change in the morphology of SBS and epoxidized SBS after exposure to the microorganisms. This is in accordance with the weight loss data where they do not show any weight loss indicating that they are not degraded by Aspergillus niger.

Figure 4 shows the change in morphology of sugar linked SBS after biodegradation. It is observed that all the sugar linked SBS samples show formation of cavities on the surface indicating degradation. Glucose linked SBS shows more cavity formation as compared to man nose linked SBS. The maltose linked SBS also shows similar behaviour and also exhibits increased surface roughness. Galactose linked SBS showed least cavity formation on the surface on account of its significantly lower biodegradability. Similarly, SEM micrographs after biodegradation with Pseudomonas sp. of sucrose linked SBS and mannose linked SBS (Figure 5) show that sucrose has greater effect on biodegradation than mannose, as confirmed by weight loss data.

Thus, SEM provided a pictorial view of biodegradation, showing cavity formation and increased surface roughness proportional to the extent of biodegradation.

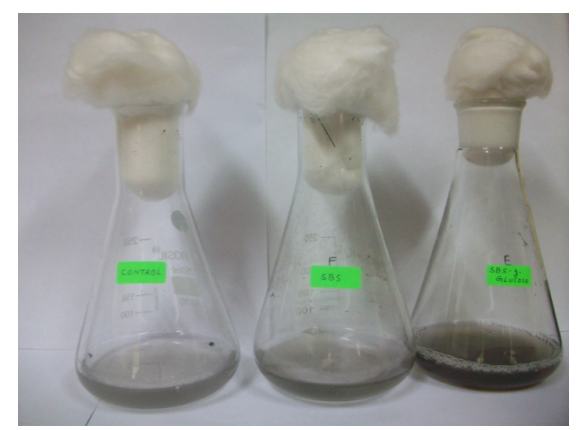

Figure 2. Photograph showing fungal growth of Aspergillus niger NCIM 1025 on functionalized SBS: (a) Control; (b) Unmodified SBS; (c) Glucose linked SBS.

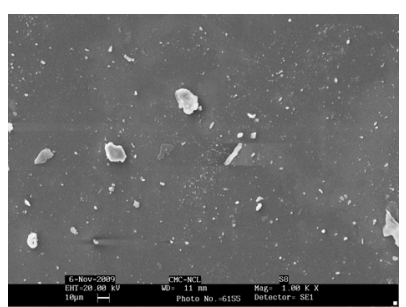

(a)

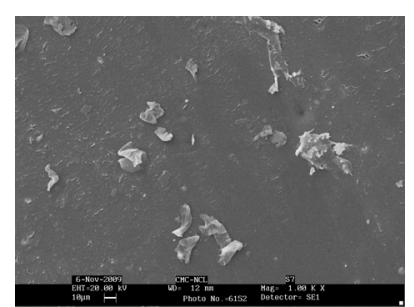

(b)
Figure 3. SEM micrographs after biodegradation of (a) SBS; (b) Epoxidized SBS.

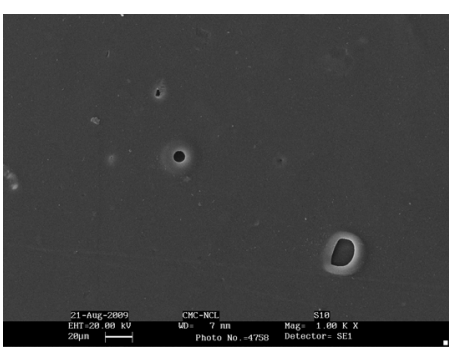

(a)

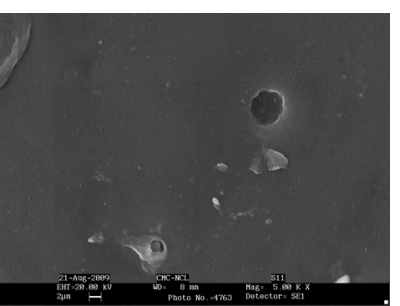

(b)

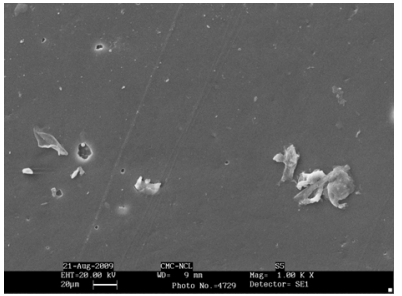

(d)

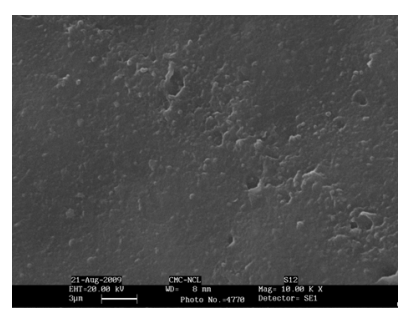

(c)

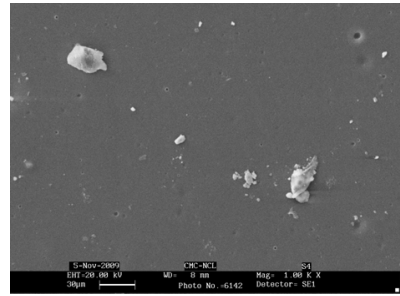

(e)
Figure 4. SEM micrographs after biodegradation of (a) glucose linked SBS; (b) mannose linked SBS; (c) maltose linked SBS; (d) sucrose linked SBS; (e) galactose linked SBS.

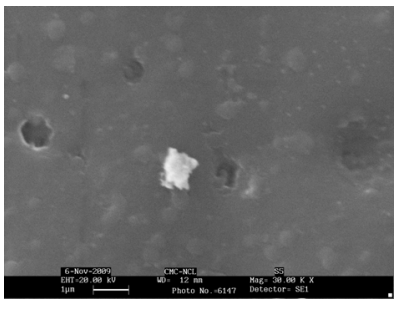

(a)

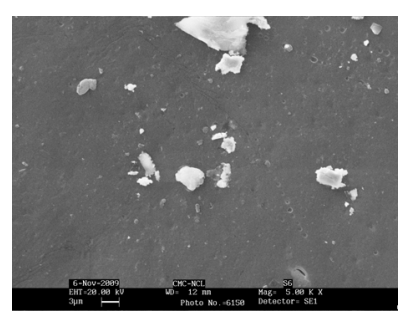

(b)
Figure 5. SEM micrographs after biodegradation with Pseudomonas sp. of (a) sucrose linked SBS; (b) mannose linked SBS.

\subsection{Antimicrobial Activity}

Polymers having quaternary ammonium and pyridinium groups are the most studied class amongst antimicrobial polymers [15-18] in general. Although the quaternary nitrogen pendants in our modified SBS samples are present in very low quantities to be effective as antimicrobial compounds, nevertheless it was pertinent to investigate their effect, if any, on the inhibition of microbial growth. Thus, antibacterial activity against common pathogenic bacteria cultures (Escherichia coli $k$-12, Bacillus sp.) and yeast cultures (Pichia stipitis NCIM 3499, 
Pichia stipitis NCIM 3497) were evaluated for the functionalized SBS elastomers. The results of antimicrobial studies are presented in Figure 6 against different micro-organisms on sugar linked SBS containing quaternary nitrogen pendants. The graphical representation of data (Figure 6) clearly shows the extent of microbial inhibition exhibited by different functionalized SBS polymers. The microbial concentration was determined by measuring the optical density of the broth [19-21] at $600 \mathrm{~nm}$ after $24 \mathrm{~h}$, the decrease in the optical density is directly proportional to effectiveness of microbial inhibition.

The results using four different microorganisms for the functionalized SBS elastomers are presented in Figure 6. In this figure, optical density (OD) obtained after $24 \mathrm{~h}$ against both bacteria and yeasts were normalized to that obtained with control (the control being unmodified SBS). As can be seen from the figure, the decrease in OD is in the range of $4 \%-24 \%$ for the functionalized SBS elastomers. A change of $24 \%$ reduction in OD is significant. Bacteria E. coli and yeast Pichia stipitis NCIM 3497 show more susceptibility to inhibition compared to Bacillus sp., and Pichia stipitis NCIM 3499, which is reflected in their respective optical densities. Therefore we can conclude that while the microorganisms continue to grow in the presence of quaternary nitrogen and sugar groups of SBS polymer, even then antimicrobial activity is undoubtedly present in some cases.

The observed inhibition of the microbial growth due to small amount of quaternary nitrogen pendants in the functionalized SBS indicates that by increasing their amounts there is good potential of making SBS elastomers as effective antimicrobial polymers.

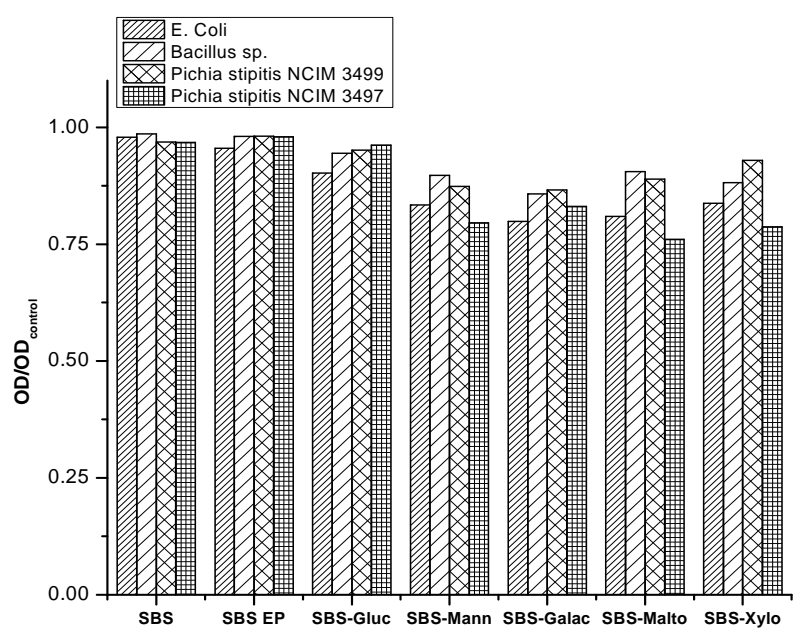

Figure 6. Normalized optical density at $600 \mathrm{~nm}$ of nutrient broth after $24 \mathrm{~h}$ in contact with functionalized SBS films with different microorganisms $E$. coli DH5 $\alpha$, Bacillus subtilis RCK (Accession no. AJ937677), Pichia stipitis NCIM 3497 and $P$. stipitis NCIM 3499.

\section{Conclusions}

We were able to illustrate that incorporation of minute quantities of sugar $(0.09-0.37 \mathrm{wt} \%)$ pendants on SBS copolymer main chain renders it biodegradable. $\sim 4-14$ fold weight loss for bacterial pseudomonas $s p$. and $\sim 7$ 36 fold weight loss for fungal cultures (Aspergillus niger) were observed as ratio of percent weight loss to percent sugar content of SBS. These results were corroborated by SEM studies, where biodegradaed samples showed distinct cavities, whereas un-degraded samples showed smooth surfaces.

Here it can also be concluded that since these functionalized SBS elastomers do inhibit some microbial cell growth (antimicrobial properties due to the quaternary $\mathrm{N}$ atoms), they can also prevent to some extent the growth of bacterial and fungal microorganisms during biodegradation studies. These may result in lower observed biodegradation than expected. Nevertheless, these results point to the unique application of anchoring minute quantities of sugars on to non-degradable hydrocarbon polymers to induce their biodegradation by bacteria and fungi. Moreover, there is an increasing demand for biodegradable food packaging materials. Since these synthesized elastomers have good film forming properties and show biodegradation due to the presence of sugars, these can be used as well for biodegradable packaging materials. This in turn can potentially reduce the environmental impacts of conventional packaging materials. There is also a good demand for polymers having antimicrobial properties; our studies show that SBS can be made into an antimicrobial packaging polymer by incorporating more quaternary $\mathrm{N}$ pendants.

\section{Acknowledgements}

Rakesh Singh thanks CSIR, New Delhi, for the award of a Senior Research Fellowship for his doctoral research, of which this paper is a part. This funding is gratefully acknowledged. The biodegradation studies were carried out by the NCIM Group of National Chemical Laboratory, Pune, and the antimicrobial studies were carried out by the Delhi University group.

\section{REFERENCES}

[1] L A.J. Varma, J. F. Kennedy and P. Galgali, "Synthetic Polymers Functionalized by Carbohydrates: Review," Carbohydrate Polymers, Vol. 56, No. 4, 2004, pp. 429445. doi:10.1016/i.carbpol.2004.03.007

[2] K. Merrett, W. Liu, D. Mitra, K. D. Camm, C. R. McLaughlin, Y. Liu, M. A. Watsky, F. Li, M. Griffith and D. E. Fogg, "Synthetic Neoglycopolymer-Recombinant Human Collagen Hybrids as Biomimetic Crosslinking Agents in Corneal Tissue Engineering," Biomaterials, Vol. 30, No. 29, 2009, pp. 5403-5408. 
doi:10.1016/j.biomaterials.2009.06.016

[3] P. Li, Y. F. Poon, W. Li, H.-Y. Zhu, S. H.Yeap, Y. Cao, X. Qi, C. Zhou, M. Lamrani, R. W. Beuerman, E.-T. Kang, Y. Mu, C. M. Li, M. W. Chang, S. S. J. Leong and M. B. Chan-Park, "A Polycationic Antimicrobial and Biocompatible Hydrogel with Microbe Membrane Suctioning Ability," Nature Materials, Vol. 10, No. 2, 2011, pp. 149156. doi:10.1038/nmat2915

[4] Y. Wang, G. A. Ameer, B. J. Sheppard and R. Langer, "A Tough Biodegradable Elastomer," Nature Biotechnology, Vol. 20, 2002, pp. 602-606. doi:10.1038/nbt0602-602

[5] J. M. Yang, H. T. Lin and W. C. Lai, "Properties of Modified Hydroxyl-Terminated Polybutadiene Based Polyurethane Membrane," Journal of Membrane Science, Vol. 208, No. 1-2, 2002, pp. 105-117. doi:10.1016/S0376-7388(02)00180-1

[6] V. P. Kirpichev and A. I. Yakubchik, "Reaction of Epoxidized cis-1,4-Polybutadiene with $p$-Aminodiphenylamine," Polymer Science U.S.S.R., Vol. 11, No. 10, 1969, pp. 2610-2617. doi:10.1016/0032-3950(69)90158-0

[7] V. P. Kirpichev, A. I. Yakubchik and G. N Maglysh, "Modification of CIS-1,4-Polybutadiene with $\beta$-Naphthylamine," Rubber Chemistry and Technology, Vol. 43, No. 5, 1970, pp. 1225-1229. doi:10.5254/1.3547320

[8] C. Alvarez, H. Bertorello and M. Strumia, "Application of Poly(Butadiene-co-Acrylic Acid)-Sucrose as Gel in the Separation of Different Substances," Journal of Applied Polymer Science, Vol. 45, No. 1, 1992, pp. 25-27. doi:10.1002/app.1992.070450103

[9] C. Alvarez, M. Strumia and H. Bertorello, "Preparation and Properties of Polymers of Carboxylated Polybutadiene Containing Sucrose," Polymer Bulletin, Vol. 19, No. 6, 1988, pp. 521-526. doi:10.1007/BF00283096

[10] P. Galgali, A. J.Varma, U. S. Puntambekar and D. V. Gokhale, "Towards Biodegradable Polyolefins: Strategy of Anchoring Minute Quantities of Monosaccharides and Disaccharides onto Functionalized Polystyrene, and Their Effect on Facilitating Polymer Biodegradation," Chemical Communications, No. 23, 2002, pp. 2884-2885

[11] P. Galgali, U. S. Puntambekar, D. V. Gokhale and A. J. Varma, "Fungal Degradation of Carbohydrate-Linked Polystyrenes," Carbohydrate Polymers, Vol. 55, No. 4, 2004, pp. 393-399. doi:10.1016/j.carbpol.2003.10.011

[12] R. Singh and A. J. Varma, "Towards Biodegradable Elastomers: Green Synthesis of Carbohydrate Functionalized
Styrene-Butadiene-Styrene Copolymer by Click Chemistry," Green Chemistry, Vol. 14, 2012, pp. 348-356. doi:10.1039/c1gc16146f

[13] R. Singh, "Carbohydrate Functionalize Synthetic Elastomers: Synthesis, Characterization and Applications," Ph.D. Thesis, National Chemical Laboratory (CSIR), Pune, 2010.

[14] M. Dubois, K. A. Gilles, J. K. Hamilton, P. A. Rebers and F. Smith, "Colorimetric Method for Determination of Sugars and Related Substances," Analytical Chemistry, Vol. 28, No. 3, 1956, pp. 350-356. doi:10.1021/ac60111a017

[15] T. R. Stratton, J. L. Rickus and J. P. Youngblood, "In Vitro Biocompatibility Studies of Antibacterial Quarternary Polymers," Biomacromolecules, Vol. 10, No. 9, 2009, pp. 2550-2555. doi:10.1021/bm9005003

[16] T. R. Stratton, J. A. Howarter, B. C. Allison, B. M. Applegate and J. P. Youngblood, "Structure-Activity Relationships of Antibacterial and Biocompatible Copolymers," Biomacromolecules, Vol. 11, No. 5, 2010, pp. 1286-1290. doi:10.1021/bm1000839

[17] E. R. Kenawy, S. D. Worley and R. Broughton, "The Chemistry and Applications of Antimicrobial Polymers: A State-of-the-Art Review," Biomacromolecules, Vol. 8, No. 5, 2007, pp. 1359-1384. doi:10.1021/bm061150q

[18] J. C. Tiller, G. Bonner, L. C. Pan and A. M. Klibanov, "Improving Biomaterial Properties of Collagen Films by Chemical Modification," Biotechnology and Bioengineering, Vol. 73, No. 3, 2001, pp. 246-252. doi:10.1002/bit.1057

[19] L. Cen, K. G. Neoh and E. T. Kang, "Surface Functionalization Technique for Conferring Antibacterial Properties to Polymeric and Cellulosic Surfaces," Langmuir, Vol. 19, No. 24, 2003, pp. 10295-10303. doi: $10.1021 / 1 \mathrm{a} 035104 \mathrm{c}$

[20] P. R. Joshi, J. McGuire and J. A. Neff, "Synthesis and Antibacterial Activity of Nisin-Containing Block Copolymers," Journal of Biomedical Materials Research Part B: Applied Biomaterials, Vol. 91B, No. 1, 2009, pp. 128-134. doi:10.1002/jbm.b.31381

[21] M.S. Benhabiles, R. Salah, H. Lounici, N. Drouiche, M. F. A. Goosen and N. Mameri, "Antibacterial Activity of Chitin, Chitosan and Its Oligomers Prepared from Shrimp Shell Waste," Food Hydrocolloids, Vol. 29, No. 1, 2012, pp. 48-56. doi:10.1016/j.foodhyd.2012.02.013 